\title{
Bronchodilator actions of xanthine derivatives administered by inhalation in asthma
}

\author{
MJ CUSHLEY, ST HOLGATE
}

From the University Department of Medicine, Southampton General Hospital, Southampton

ABSTRACT The airway response to the inhalation of four alkyl xanthines was studied in 17 subjects with moderately severe asthma (mean FEV 1.19 litres, $42 \%$ predicted). Theophylline $(10 \mathrm{mg} / \mathrm{ml})$, glycine theophyllinate $(50 \mathrm{mg} / \mathrm{ml})$, theophylline ethylenediamine (aminophylline $50 \mathrm{mg} / \mathrm{ml})$, and diprophylline $(125 \mathrm{mg} / \mathrm{ml})$ were administered by nebulisation and the airway response was measured as percentage change from baseline of specific airway conductance (sGaw). All xanthine derivatives had an unpleasant taste and produced coughing at the onset of nebulisation. All four xanthines produced a significant increase in sGaw by comparison with saline placebo, with a maximum mean increase from baseline of $35 \%$ for theophylline, $40 \%$ for glycine theophyllinate, $60 \%$ for aminophylline, and $32 \%$ for diprophylline. Inhalation of $200 \mu \mathrm{g}$ salbutamol from a metered dose inhaler produced an additional increase in sGaw of $149 \%$. Thus alkyl substituted xanthines administered by inhalation to patients with asthma cause significant short lived bronchodilatation, but this effect is small compared with that of a conventional dose of an inhaled $\beta_{2}$ adrenoceptor agonist.

Methylxanthines such as theophylline and aminophylline have been used for the treatment of asthma since $1922^{1}$ and currently many preparations are available for oral, rectal, and parenteral administration. The narrow therapeutic index of these drugs and the wide intersubject variations of metabolism have, however, hindered their use as first line treatment for asthma in Europe. Over the last five years the introduction of serum drug concentration monitoring, together with the availability of oral slow release preparations, has led to the increased use of theophylline and related compounds as adjuncts to other forms of asthma treatment. The accepted serum therapeutic range of 10-20 $\mu \mathrm{g}$ theophylline/ml $(55-110 \mu \mathrm{mol} / \mathrm{l})$ represents a compromise between clinical efficacy and toxicity. ${ }^{2}$ In clinical practice extremes of both toxic and subtherapeutic theophylline concentrations are frequently found, which emphasises the need for drug concentration monitoring if these drugs are to be used effectively. ${ }^{3}$

An alternative approach is to widen the therapeu-

Address for reprint requests: Dr MJ Cushley, Medicine 1, D Level, Centre Block, Southampton General Hospital, Southamptom SO9 4XY.

Accepted 9 November 1984 tic index of methylxanthines by administering them by inhalation, in line with $\beta$ adrenoceptor agonists, corticosteroids, sodium cromoglycate, and anticholinergic agents. ${ }^{4}$ Adminstration of drugs by inhalation is preferable to the oral route because it allows high doses to be delivered directly to the airways for a specific pharmacological effect with low systemic concentration and few side effects. A theophylline preparation for inhalation would offer many advantages. Few studies have been carried out with inhaled xanthine derivatives and in these any small improvement in pulmonary function has been outweighed by their unpleasant taste and irritant properties. $^{56}$

We have investigated the bronchodilator effects of four alkyl substituted xanthines administered by inhalation to patients with moderately severe asthma. The preparations selected were theophylline, two more soluble theophylline salts, aminophylline and glycine theophyllinate, and an $\mathrm{N}-7$ substituted xanthine derivative, diprophylline, which is currently available for parenteral use (Silbephylline).

\section{Methods}

Seventeen patients (nine men, eight women) took part in the study. All patients attended the out- 
Characteristics of the patients

\begin{tabular}{|c|c|c|c|c|c|c|}
\hline Patient No & Sex & Age (y) & $F E V_{1}(l)$ & $\begin{array}{l}F E V_{1} \\
\text { (\% predicted) }\end{array}$ & $\begin{array}{l}s G a w \\
\left(s^{-1} k P a^{-1}\right)\end{array}$ & Treatment* \\
\hline $\begin{array}{r}1 \\
2 \\
3 \\
4 \\
5 \\
6 \\
7 \\
8 \\
9 \\
10 \\
11 \\
12 \\
13 \\
14 \\
15 \\
16 \\
17\end{array}$ & $\begin{array}{l}\mathbf{M} \\
\mathbf{F} \\
\mathbf{M} \\
\mathbf{F} \\
\mathbf{F} \\
\mathbf{F} \\
\mathbf{F} \\
\mathbf{M} \\
\mathbf{M} \\
\mathbf{F} \\
\mathbf{F} \\
\mathbf{M} \\
\mathbf{M} \\
\mathbf{F} \\
\mathbf{M} \\
\mathbf{M} \\
\mathbf{M}\end{array}$ & $\begin{array}{l}61 \\
49 \\
53 \\
49 \\
56 \\
52 \\
31 \\
39 \\
45 \\
27 \\
32 \\
62 \\
61 \\
60 \\
51 \\
66 \\
31\end{array}$ & $\begin{array}{l}1.12 \\
1.09 \\
1.37 \\
0.82 \\
1.50 \\
0.70 \\
1.34 \\
0.95 \\
1.35 \\
2.04 \\
1.27 \\
1.45 \\
1.37 \\
1.19 \\
1.28 \\
0.71 \\
0.75\end{array}$ & $\begin{array}{l}35 \\
38 \\
48 \\
34 \\
66 \\
33 \\
47 \\
25 \\
37 \\
61 \\
47 \\
49 \\
46 \\
56 \\
39 \\
24 \\
21\end{array}$ & $\begin{array}{l}0.39 \\
0.60 \\
0.31 \\
0.29 \\
0.41 \\
0.37 \\
0.36 \\
0.22 \\
0.29 \\
0.80 \\
0.49 \\
0.35 \\
0.33 \\
0.72 \\
0.46 \\
0.33 \\
0.19\end{array}$ & $\begin{array}{l}\text { S, B } \\
\text { Prt, S, B } \\
\text { S, B } \\
\text { S } \\
\text { S, B } \\
\text { Prt, S, B } \\
\text { S, B, Theo } \\
\text { Prt, S, B, SCG } \\
\text { Prt, S, B } \\
\text { B, Fen } \\
\text { Prt, SCG, S } \\
\text { S } \\
\text { Pr†, B, Iso, Ip } \\
\text { S, B } \\
\text { B, Theo } \dagger \\
\text { S } \\
\text { Pr } \dagger \text {, S }\end{array}$ \\
\hline $\begin{array}{l}\text { Mean } \\
\text { SEM }\end{array}$ & . & & $\begin{array}{l}1.19 \\
0.08\end{array}$ & $\begin{array}{r}41.5 \\
3.1\end{array}$ & $\begin{array}{l}0.41 \\
0.04\end{array}$ & \\
\hline
\end{tabular}

*All drugs given by inhalation except for those marked $\dagger$. S-salbutamol; B-beclomethasone dipropionate; Pr-prednisolone; Ip-ipratropium bromide; Iso-isoprenaline; SCG-sodium cromoglycate; Fen-fenoterol; Theo-theophylline.

†Administered orally.

patient clinics of the respiratory unit and had moderately severe asthma with a documented improvement in $\mathrm{FEV}_{1}$ of more than $15 \%$ after $200 \mu \mathrm{g}$ inhaled salbutamol. Patients were non-smokers; details of age, sex, pulmonary function and treatment are shown in the table. None of the subjects were taking oral $\beta$ adrenoceptor agonists and all inhaled bronchodilators were omitted for eight hours before each visit. Treatment with oral and inhaled corticosteroids was continued as usual. Two patients were receiving oral theophylline preparations and these were omitted for 24 hours before the study days. All subjects gave informed consent and the study was approved by the Southampton ethical committee.

Four xanthine preparations and saline placebo were used in the study. Because of spontaneous fluctuations in the severity of asthma and intercurrent illness not all the subjects were able to receive all four preparations. Micronised theophylline and glycine theophyllinate (both from Riker Laboratories, Loughborough) were dissolved in saline to produce concentrations of $10 \mathrm{mg} / \mathrm{ml}$ (pH 5.0) and $50 \mathrm{mg} / \mathrm{ml}$ (pH 9.1) respectively. Theophylline ethylenediamine (aminophylline $250 \mathrm{mg} / \mathrm{ml}$, Antigen Ltd, Roscrea, Ireland) was diluted with saline to a concentration of $50 \mathrm{mg} / \mathrm{ml}$ (pH 9.4) and diprophylline $125 \mathrm{mg} / \mathrm{ml} \mathrm{(pH} \mathrm{5.4)} \mathrm{was}$ prepared similarly by diluting the commercial solubilised parenteral preparation Silbephylline $(250 \mathrm{mg} / \mathrm{ml}$, Berk Pharmaceuticals Ltd, Eastbourne). Sodium chloride $0.9 \%$ (pH 5.2) was used as placebo control.
The solutions were administered in random order from a volume of $4 \mathrm{ml}$ in a disposable Inspiron Mini-Neb nebuliser (CR Bard, Sunderland), driven by compressed air at $81 \mathrm{~min}^{-1}$. Inhalation was by tidal breathing for 10 minutes, the Mini-Neb nebulisers being changed every 2.5 minutes. With this technique ${ }^{7}$ the amount of each drug leaving the nebuliser and inhaled by the patient was $6 \mathrm{mg}$ for theophylline, $30 \mathrm{mg}$ for aminophylline, $30 \mathrm{mg}$ for glycine theophyllinate, and $75 \mathrm{mg}$ for diprophylline.

Airway calibre was measured before and after nebulisation as airway resistance with a constant volume pressure conpensated whole body plethysmography (Fenyves and Gut, Basle, Switzerland) while subjects were panting at two cycles a second for 12 seconds. The plethysmograph signals were computed by an on line microprocessor and expressed as specific airway conductance (sGaw).

All studies commenced in the morning, between 0800 and 0900 hours. On arrival in the laboratory subjects rested for 20 minutes before baseline measurements of $\mathrm{FEV}_{1}$ (six recordings) and sGaw (five recordings) were made. Subjects then received 10 minute inhalations of saline or one of the xanthine preparations. The study was single blind and the subjects had been advised that some of the preparations would have a bitter taste but that this did not necessarily reflect an active preparation. After each inhalation measurements of $\mathbf{s G a w}$ were made at $\mathbf{1}$, $3,5,10,15,20,25$, and 30 minutes. On completion of the last-recordings subjects inhaled $200 \mu \mathrm{g}$ salbutamol from a metered dose inhaler and a further measurement of sGaw was made after 15 minutes. 

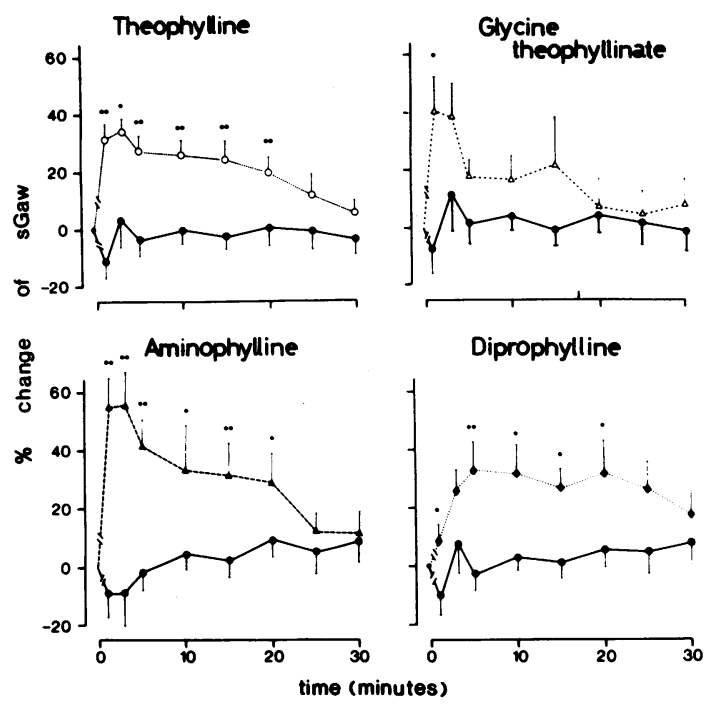

Mean (SEM) percentage change of sGaw from baseline after inhalation of theophylline $(n=14)$, aminophylline $(n=12)$, glycine theophyllinate $(n=10)$, diprophylline $(n=13)$, and saline (lower curve in each case). ${ }^{*} p<0.05$; ${ }^{* *} p<0.01$.

STATISTICAL ANALYSIS

Comparisons of baseline values of $\mathrm{FEV}_{1}$ and $\mathrm{sGaw}$ were analysed by Student's $t$ test for paired data and Wilcoxon's signed rank test respectively. After each inhalation, change in airway calibre was expressed as the percentage change in sGaw from the mean baseline value. At each measurement at the various intervals after inhalation the response following each of the xanthine derivatives was compared with that following saline by Wilcoxon's signed rank test. The response following salbutamol was expressed as the additional percentage increase in sGaw after the 30 minute measurement.

\section{Results}

The subjects had a mean (SEM) baseline $\mathrm{FEV}_{1}$ of $1.19(0.08)$ litres (42\% predicted) and sGaw 0.41 $(0.04) \mathrm{s}^{-1} \mathrm{kPa}^{-1}$. For each subject $\mathrm{FEV}_{1}$ values varied by less than $15 \%$ between study days.

All xanthine inhalations had an unpleasant taste. This was most noticeable with the more concentrated aminophylline and diprophylline. Subjects varied in their subjective responses to the inhalations, but coughing during the first minute was frequent with all the xanthines.

All four xanthine preparations produced a significant increase in sGaw by comparison with saline placebo (fig). The response was rapid, reaching a peak within five minutes. The xanthine induced increase in sGaw was short lived, the values not being significantly different from those observed with saline placebo at 30 minutes. In the concentrations given there were no significant differences in the time course-response curves for any of the four xanthines.

Inhalation of $200 \mu \mathrm{g}$ salbutamol from a metered dose inhaler produced an additional increase in sGaw of $135 \%(24 \%)$ after saline placebo, $150 \%$ $(20 \%)$ after theophylline, $160 \%(27 \%)$ after aminophylline, $135 \%(23 \%)$ after diprophylline, and $150 \%(28 \%)$ after glycine theophyllinate. There was no significant difference in the response to salbutamol whether preceded by inhaled saline or any of the xanthine preparations.

\section{Discussion}

In this group of patients with moderately severe asthma inhaled theophylline and related xanthines given as a nebulised aerosol produced a rapid but short lived bronchodilatation (fig). The degree of bronchodilatation was small compared with that produced by a conventional dose of inhaled salbutamol $(200 \mu \mathrm{g})$ from a metered dose inhaler. All the xanthines had an unpleasant taste and produced coughing early during the inhalation, particularly the more concentrated preparations aminophylline and diprophylline.

Information on inhaled xanthine derivatives for the treatment of asthma is scant and incomplete. Two early studies ${ }^{89}$ using inhaled theophylline and aminophylline were encouraging, though the bronchodilatation reported was short lived. In the $1960 \mathrm{~s}$ two uncontrolled studies reported definite benefit with inhaled aminophylline..$^{10}$ " A controlled study found aminophylline too irritant to be clinically useful, although one theophylline salt, neuphylline, did produce significant bronchodilatation. ${ }^{12}$ In 1976 Stewart and Block reported no useful bronchodilator effect of inhaled aminophylline, though only $62.5 \mathrm{mg}$ was nebulised over five minutes and the first measurement of $\mathrm{FEV}_{1}$ was 20 minutes after completion of nebulisation. ${ }^{13}$ Four subsequent studies have reported improvement in airway function with inhaled aminophylline and theophylline..$^{561415}$ The studies reported here used various drug concentrations and methods of inhalation.

The present study was designed to investigate the bronchodilator efficacy of maximally tolerated concentrations of four alkyl substituted xanthine preparations. The main limitation to dose was the solubility of the compounds and the unpleasant taste and pronounced cough produced by the concentrated preparations. We made no attempt to obtain concentration-response data. With all four xanthine derivatives inhalation produced bronchodilatation 
as reflected by an increase in sGaw, but at best the response was only $49 \%$ of that achieved with $200 \mu \mathrm{g}$ inhaled salbutamol. The reason for the low bronchodilator efficacy of inhaled xanthines is at first sight difficult to explain since it has been proposed that these drugs and the $\beta_{2}$ adrenoceptor agonists cause bronchodilatation through the same final pathway, by increasing concentrations of cyclic AMP in airway smooth muscle..$^{16}$ One explanation may be limited retention of inhaled xanthines in the airways, so that local concentrations are insufficient to produce an optimal bronchodilator effect. Wich oral and intravenous theophylline therapeutic efficacy is closely related to circulating drug concentrations and if serum concentrations are not maintained the airway effects are rapidly lost. In studies of inhaled methylxanthines for asthma serum theophylline concentrations have always been below $5 \mu \mathrm{g} / \mathrm{ml}$ and often undetectable. ${ }^{5615}$ We did not measure serum concentrations but with the total amount of each drug inhaled concentrations of acccepted therapeutic significance are most unlikely to have been achieved. The very rapid response with the inhaled route implies a local action of xanthines in the airways and the short duration of effect suggests rapid removal of the drug from its site of action.

Our results are in agreement with those of most other studies on inhaled methylxanthines in that the effect produced was very much less than that of a standard dose of inhaled $\beta$ adrenoceptor agonist. $^{5613}$ Furthermore, the relatively small bronchodilator action was offset by the unpleasant taste and irritant properties of the xanthines. We conclude that the xanthine derivatives used in this study when administered by inhalation are unlikely to be of benefit in the treatment of asthma.

We are very grateful to Riker Laboratories Ltd for supplying theophylline and glycine theophyllinate and to Mrs S Foulkes for typing the manuscript.

\section{References}

1 Hirsch S. Klinischer und Experimenteller Beitrag zur Krampflosenden wirkung der purin-derivate. Klin Wochenschr 1922;1:615.

2 Anonymous. Theophylline benefits and difficulties. Lancet 1983;ii:607-8.

3 Woodcock AA, Johnson MA, Geddes DM. Theophylline prescribing, serum concentrations and toxicity. Lancet 1983;ii:610-2.

4 Clarke SW, Newman SP. Therapeutic aerosols. 2Drugs available by the inhaled route. Thorax 1984;39: 1-7.

5 Kandt D, Ivainsky H, Sehrt I. Efficacy of theophylline aerosols in obstructive lung diseases. Respiration 1981;42:278-82.

6 Bohądana AB, Peslin R, Teculesu D, Polu JM, Belleville F, Massin N. The bronchodilator action of theophylline aerosol in subjects with chronic airflow obstruction. Bull Euro Physiop Respir 1980;16:13-24.

7 Lewis RA, Cushley MJ, Fleming JS, Tattersfield AE. Is a nebuliser less efficient than a metered dose inhaler and do pear-shaped extension tubes work? Am Rev Respir Dis 1982;125:94.

8 Prigal SJ, Brooks AM, Harris R. The treatment of asthma by inhalation of aerosol of aminophylline. $J$ Allergy 1947;18:16-28.

9 Taplin GV, Gropper AL, Scott G. Micropowdered aminophylline or theophylline inhalation therapy in chronic bronchial asthma. Evaluation by recorded vital capacity changes. Ann Allergy 1949; 7:513-23.

10 Horton GE. The value and safety of nebulised aminophylline in acute bronchial asthma. J Tenn Med Ass 1966;59:239-44.

11 Kramarenko MP. Treatment of bronchial asthma with euphyllin aerosols (preliminary report). Clin Med 1961;39:110-2.

12 Aepli R. Clinical pharmacology of bronchospasmolytics in the asthmatics. Helv Med Acta 1969;34:517-31.

13 Stewart BN, Block AJ. A trial of aerosolised theophylline in relieving bronchospasm. Chest 1976;69:718-21.

14 Greger G. Functional trials on the effectiveness of inhaled aminophylline. Atemwegs-und Lungenkrankheiten 1978;4:414-7.

15 Greger $\mathrm{G}$. Testing of lung function after theophylline inhalation. Z Erkrank Atm-Org 1981;157:270-5.

16 Anonymous. Cyclic AMP: The Second Messenger. Lancet 1970;ii: 1119-21. 